\title{
Desirability Function Analysis (DFA) in Multiple Responses Optimization of Abrasive Water Jet Cutting Process
}

\author{
Andrzej Perec ${ }^{1}$ \\ ${ }^{1}$ The Jacob of Paradies University, Faculty of Technology, Poland, e-mail: aperec@ajp.edu.pl
}

\begin{tabular}{l}
\hline \hline Article Info \\
\hline Article history: \\
Received September 20, 2021 \\
Revised October 28, 2021 \\
Accepted November 16, 2021 \\
\hline
\end{tabular}

\section{Keywords:}

Abrasive water jet, Cutting depth,

Surface roughness, Desirability function.

\begin{abstract}
This paper introduces optimization of machining parameters for highpressure abrasive water jet cutting of Hardox 500 steel utilizing desirability function analysis (DFA). The tests were carried out according to the orthogonal matrix (Taguchi) L9. The control parameters of the process such as pressure, abrasive flow rate, and traverse speed was optimized under multi-response conditions namely cutting depth and surface roughness. The optimal set of control parameters was established on the basis of the composite desirability value obtained from desirability function analysis and the significance of these parameters was determined by analysis of variance (ANOVA). The effects show that optimal sets for high cutting depth and small surface roughness is high pressure, middle abrasive flow rate, and small traverse speed. A confirmation test was also leaded to validate the test results. Results of the research have shown that machining efficiency at keeping good level quality of cut surface can be improved this approach.
\end{abstract}

Copyright (C) 2020 Regional Association for Security and crisis management and European centre for operational research. All rights reserved.

\section{Corresponding Author:}

Andrzej Perec,

The Jacob of Paradies University, Faculty of Technology; email: aperec@ajp.edu.pl

\section{Introduction}

In order to increase the production efficiency, special attention is paid to the optimization of the production technology. The rapid development of the IT field contributed to the fact that the methods of solving optimization tasks (A Radomska-Zalas, et al. 2019), (A Radomska-Zalas, and Perec, 2019), (Gostimirovic et al. 2019) became the subject of research in many research centers.

Desirability function analysis (DFA) assures a real solution to the uncertainty in multiple research data issues. It can be exploited for the complicated manufacturing processes to multi-level optimize by converting the multi response characteristics into a single response function. DFA is an efficient method to examine the relational degree among discrete sequences. Its additional advantage is possibility to analyze of many factors from less available data. It does not engage too tangled mathematical theory and thus can be used by engineers without deep statistical experience.

Research effect of carbon epoxy composite material machining by abrasive water jet was published by Dhanawade and Kumar (Dhanawade and Kumar 2019). Properties of surface morphology, kerf formation and kerf surface features were studied to understand the basic mechanism of cutting. The influence of hydraulic pressure, traverse speed, stand-off distance and abrasive mass flow rate have been tested. The design of experiments using response surface methodology was performed and models to prediction surface roughness and kerf taper was developed. Further, a multi-response optimization was performed on the ground of desirability function to enhance the cut kerf properties. 
The machinability research in the turning of hard D3 steel with carbide, ceramic, and coated ceramic tool presented Lakhdar et al. (Lakhdar et al. 2020.) The results of the machining follow control parameters: depth of cut, tool, speed, and the tool feed rate on the output parameters as surface roughness and the cutting force was tested. The modeling of cutting effects was performed using RSM and ANN methods. Additionally, a multi-criteria optimization availing the Desirability Function Analysis was performed. The optimal level of the control factors for the total desirability was finally identified with a maximal error of $2.94 \%$.

The investigation of the welding parameters optimization designed for friction stir welding (FSW) of aluminum-magnesium alloy (AA5052) was introduced by Chanakyan et al. (C. Chanakyan and S. Sivasankar 2020). The experiments were conducted by selecting the different welding process control parameters as tool rotation and traverse speed, and tool pin profiles. The pin profile was made with ceramic tool. Taguchi-based Desirability Function Analysis (DFA) engaged in establishing the optimal process parameters with multiobjective function to maximize the tensile strength and the nugget hardness. The welding parameter of the optimum level was attained by the highest composite desirability value. An effect noticed that the tool pin profiles, and tool rotational speed are the important factors to influence the mixed output responses. On basis of the contour plots and mean effect authors show that the interaction of parameters of welding on the required output response was significant.

Alagarsamy et al. developed a mathematical model (Alagarsamy et al. 2021) and predict the machining performance characteristics of the electric discharge machining (EDM) process using response surface methodology (RSM) coupled with the desirability function approach (DFA). The effect of various factors, such as electrode material, pulse current, pulse ON time, and pulse OFF time were selected as input process parameters with an objective to maximize the material removal rate, minimize the surface roughness, and electrode wear ratio. The machining was conducted on $\mathrm{Al}-\mathrm{Zn}-\mathrm{Mg}-\mathrm{Cu}$ (AA7075) alloy composite reinforced with $10 \% \mathrm{TiO} 2$ particles produced by stir casting route. Experimental results show that pulse current and pulse ON time are the most significant factors for MRR and SR while electrode materials and pulse current have a notable effect on EWR. Finally, multi-response optimization was performed to predict the EDM parameters by using DFA and the optimum combination of control parameters was identified.

Devarajaiah et al. (Devarajaiah and Muthumari 2018) also were presented the research of cutting by the EDM. In this paper, wire EDM experiments on titanium alloy are conducted using Taguchi L16 array. Desirability function analysis (DFA) was used to simultaneously optimize the responses. The control parameters were optimized using DFA, and results show an improvement in composite desirability factor by $7.88 \%$ at the optimum parameter setting.

Panda et al. (Panda et al. 2020) presented the application of Taguchi-based MOORA technique, desirability function analysis, and TOPSIS method for optimizing the surface roughness chromoly steel treated by ECM with the help of hexagonal-shaped brass electrode and brine solution. Multi-objective optimization has been done to investigate the influence of process parameters, i.e., voltage, tool feed rate, and signal on MRR and surface roughness. The optimal factor setting obtained from each optimization technique was compared, and the confirmation test was done to validate the results obtained from electrochemical machining.

Based on the analysis of the literature, it can be concluded that the DFA analysis is an interesting multioptimization method used in advanced production methods. Therefore, it was decided to use a method for multi-criteria optimization in abrasive waterjet treatment.

\section{Materials and methods}

\subsection{Cut material}

Hardox 500 steel was used as the target material. Hardox 500 is a wear-resistant steel grade with a hardness of $470-530 \mathrm{HB}$. It is the most popular of Hardox grade and most often chosen by users. Due to the relatively high hardness, cutting with traditional methods is possible, but they are characterized by low efficiency. Chemical composition presents Table 1 .

Table 1. Chemical composition of Hardox 500 steel (SSAB Homepage)

\begin{tabular}{cccccccccc}
\hline \multirow{2}{*}{ Grade } & $\begin{array}{c}\mathrm{C} \\
\max \%\end{array}$ & $\begin{array}{c}\mathrm{Si} \\
\max \%\end{array}$ & $\begin{array}{c}\mathrm{Mn} \\
\max \%\end{array}$ & $\begin{array}{c}\mathrm{P} \\
\max \%\end{array}$ & $\begin{array}{c}\mathrm{S} \\
\max \%\end{array}$ & $\begin{array}{c}\mathrm{Cr} \\
\max \%\end{array}$ & $\begin{array}{c}\mathrm{Ni} \\
\max \%\end{array}$ & $\begin{array}{c}\mathrm{M} \text { max } \% \\
\max \%\end{array}$ \\
\hline Sheet & 0.27 & 0.50 & 1.60 & 0.025 & 0.010 & 1.20 & 0.25 & 0.25 & 0.005 \\
Plate & 0.30 & 0.40 & 1.30 & 0.020 & 0.010 & 2.20 & 2.0 & 0.40 & 0.005 \\
\hline
\end{tabular}




\subsection{Abrasive material}

As abrasive material the garnet type J80A from Jinhong Mining, China deposit was used. Abrasive particle distribution presents Fig. 1.

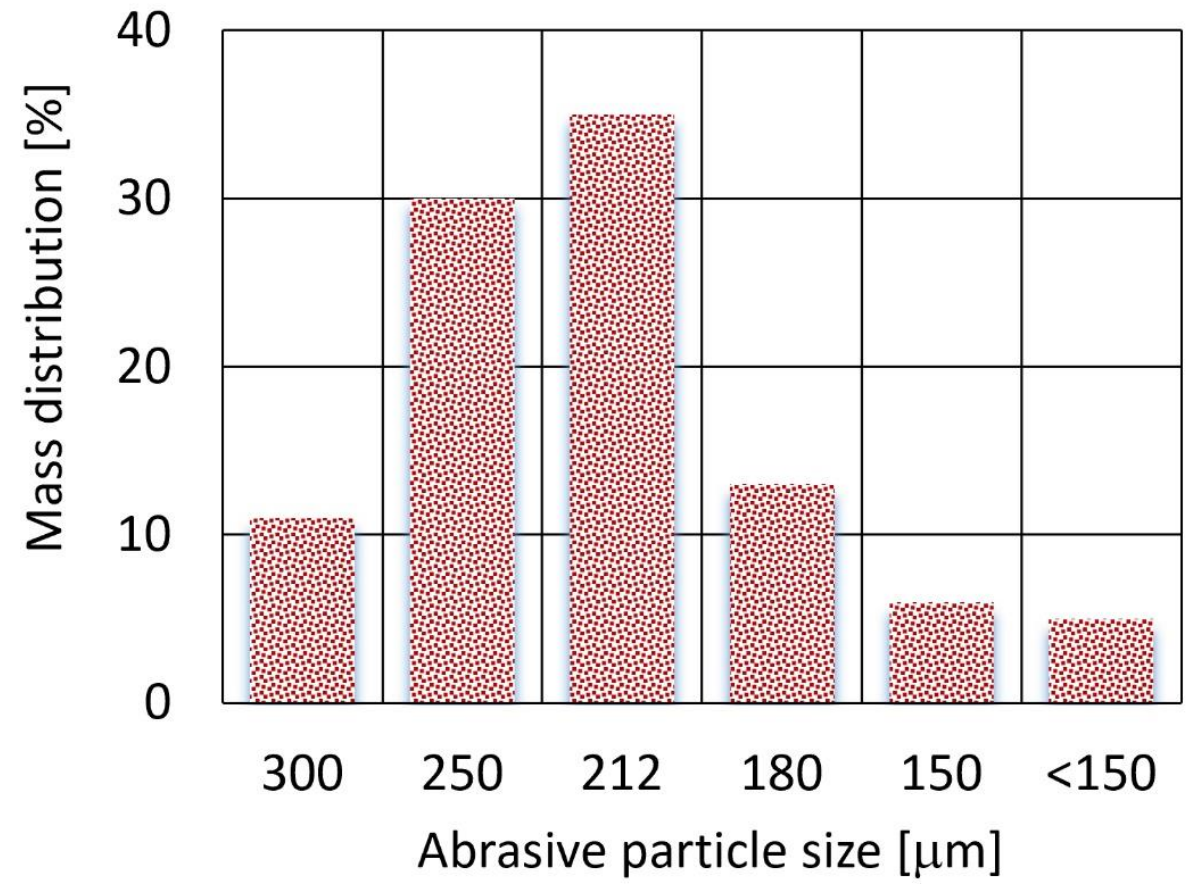

Figure 1. Typical particle distribution of J80A garnet

The shape of grains is near isometric. Particles are characterized by sharp edges and corners. Its color is from light to deep violet with smaller number dark brown to black. Mineral content, chemical composition and physical characteristics presents Table 2 .

Table 2. Properties of garnet abrasive material (Jinhong Mining Catalog of Products 2019)

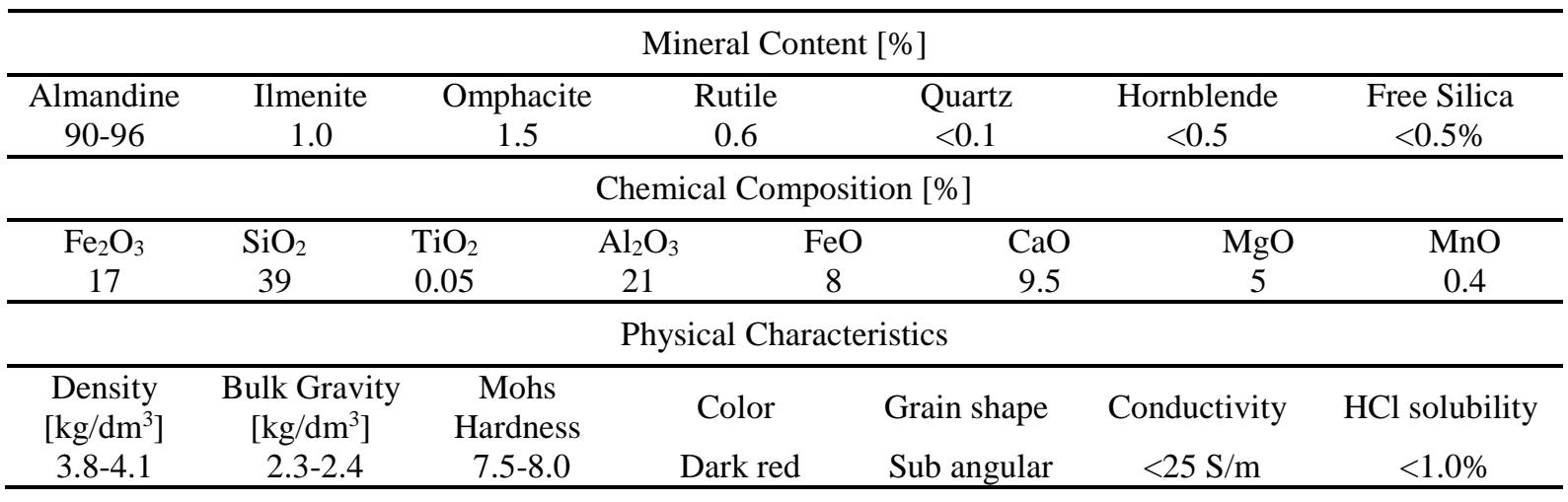

\subsection{Desirability function analysis (DFA)}

As in other optimization methods based on decision support methods (Aleksandra Radomska-Zalas and Fajdek-Bieda 2021), (Fajdek-Bieda 2021), also in this case, the characteristics of the expected effect were defined.

DFA relies on transform the multi response characteristics into single response function, named composite desirability $\left(\mathrm{D}_{\mathrm{g}}\right)$. To achieve this effect, the analysis should be carried out in the following steps:

Step 1 Calculation of desirability index

Calculating the individual desirability $\left(d_{i}\right)$ comes for each response on ground the equations, published by Harrington (Harrington 1965) and extended by Derringer and Suich (Derringer and Suich 1980). Aptly to the response characteristics may occur three aspects of the desirability functions.

Desirability Function Analysis (DFA) in Multiple Responses Optimization of Abrasive ... (Andrzej Perec) 
In the case when the output parameter is favorable and it takes the highest possible values (larger is better), the index $d_{i}$ is described as follows:

$$
d_{i}=\left\{\begin{array}{l}
0, y_{i} \leq y_{\min } \\
\left(\frac{y_{i}-y_{\min }}{y_{\max }-y_{\min }}\right)^{r}, y_{\min } \leq y_{i} \leq y_{\text {max }}, r \geq 0 \\
1, y_{i} \geq y_{\min }
\end{array}\right.
$$

Where:

$d_{i}$ is the individual desirability,

$y_{i}$ is the expected value,

$y_{\min }$ is the lower tolerance limit,

$y_{\max }$ is the upper tolerance limit,

$r$ is the weight.

When the $y_{i}$ exceeds a certain criteria value, which can be viewed as the requirement, the desirability value equals 1 . If the $y_{i}$ is less than a specified criteria value, which is unsuitable, the desirability equals 0 .

If the output parameter is favorable when it takes the smallest possible value (smaller the better), the factor $d_{i}$ is defined as follows:

$$
d_{i}=\left\{\begin{array}{l}
1, y_{i} \leq y_{\min } \\
\left(\frac{y_{i}-y_{\max }}{y_{\min }-y_{\max }}\right)^{r}, y_{\min } \leq y_{i} \leq y_{\max }, r \geq 0 \\
0, y_{i} \geq y_{\min }
\end{array}\right.
$$

When the $y_{i}$ is less than a certain criteria value, the desirability value equals 1 . If the $y_{i}$ oversteps the specific value, the desirability value equals 0 .

However, in the case when the output parameter is the most favorable (nominal is the best) when it takes the nominal values, the index $d_{i}$ is described as follows:

$$
d_{i}=\left\{\begin{array}{c}
\left(\frac{y_{i}-y_{\min }}{T-y_{\min }}\right)^{s}, y_{\min } \leq y_{i} \leq T, s \geq 0 \\
\left(\frac{y_{i}-y_{\min }}{T-y_{\min }}\right)^{t}, T \leq y_{i} \leq y_{\max }, t \geq 0 \\
0
\end{array}\right.
$$

Where:

$T$ is the individual target value,

$s$ and $t$ are the weight.

In this case the $y_{i}$ value is required to achieve a particular target T. When the $y_{i}$ equals $T$, the desirability value equals 1 . If the value of $y_{i}$ cross a particular range, the desirability value equals 0 , and presents the worst case.

The $r, s$ and $t$ weights are defined aptly to the user demand. If the proper response is looked to be near to the target, the weight can assume a larger value. In another case, the weight can accept the minor value.

Step 2 Calculation the composite desirability

The individual desirability factor of all responses is combined to single value using following equation:

$$
d_{G}=\sqrt[w]{\left(d_{1}^{w 1} \times d_{2}^{w 2} \cdots d_{i}^{w i}\right)}
$$

Where:

$d_{G}$ is the Composite Desirability or overall desirability,

$d_{i}$ and $w_{i}$ are the individual desirability and weight of the response $y_{i}$,

$w$ is the sum of the individual weights. 
Step 3. Determine the optimum level parameters and its combination.

Establishing the optimal level control parameters combination. The high composite desirability value suggests high processing quality.

Step 4. Calculate the predicted optimum conditions.

\subsection{Surface roughness}

Most popular surface roughness parameter $S_{a}$ (Balasz, Szatkiewicz, and Krolikowski 2007), (Krolczyk, Kacalak, and Wieczorowski 2021) shows a the mean of the average height difference for the average plane. It gives steady effects because is not substantially affected by scratches, contamination, and measurement noise and the spacing of the varied texture assets. However, for a AWJ surface cut, using this parameter may bring a not very unreliable effect (Perec 2021). This is due to the specific machining marks (Fig. 2).
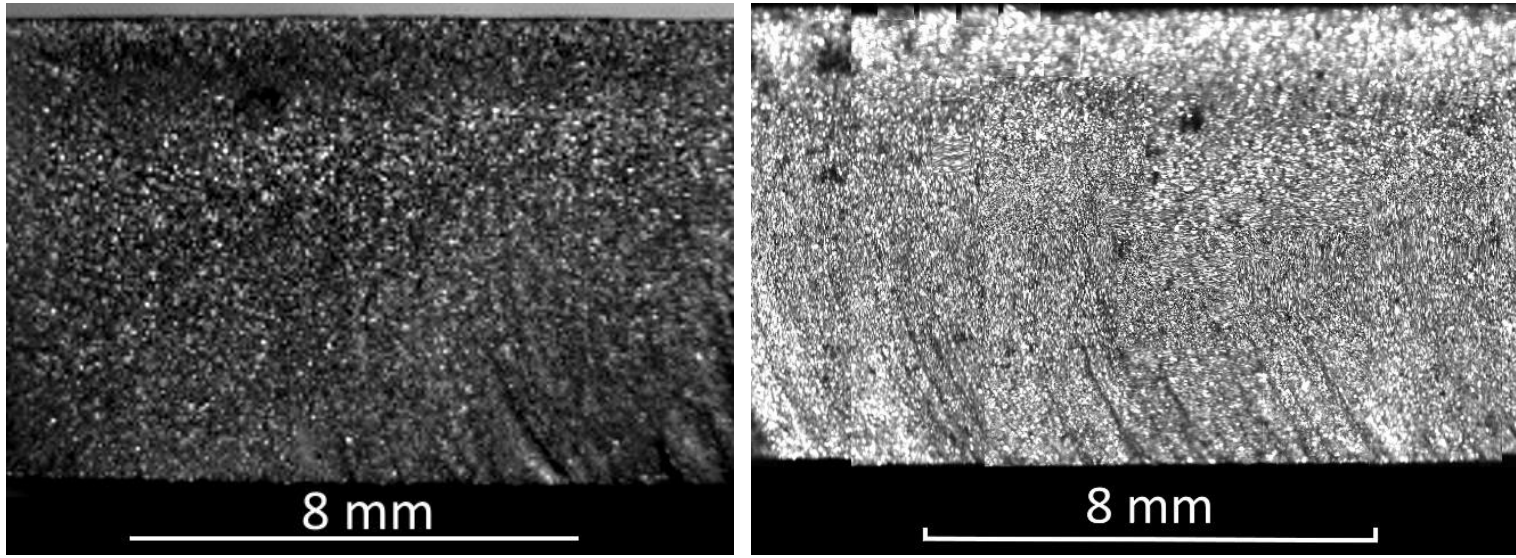

Figure 2. Sample AWJ cut surface: a) optical microscope view, b) SEM view

Therefore, a different surface roughness factor $S_{z}$ was considered. $S_{z}$ factor extends the contour (line roughness) factor $R_{z}$ three-dimensionally (Fig. 3). The maximal height $S_{z}$ is corresponding to the sum of the maximal peak height $S_{p}$ and maximal valley depth $S_{v}$, as shown in Eq. 5.

$$
S_{z}=\max [Z(x, y)]+|\min [Z(x, y)]|
$$

While is often used, this factor is substantially affected by scratches, contamination, and measurement noise due to its use of peak values.

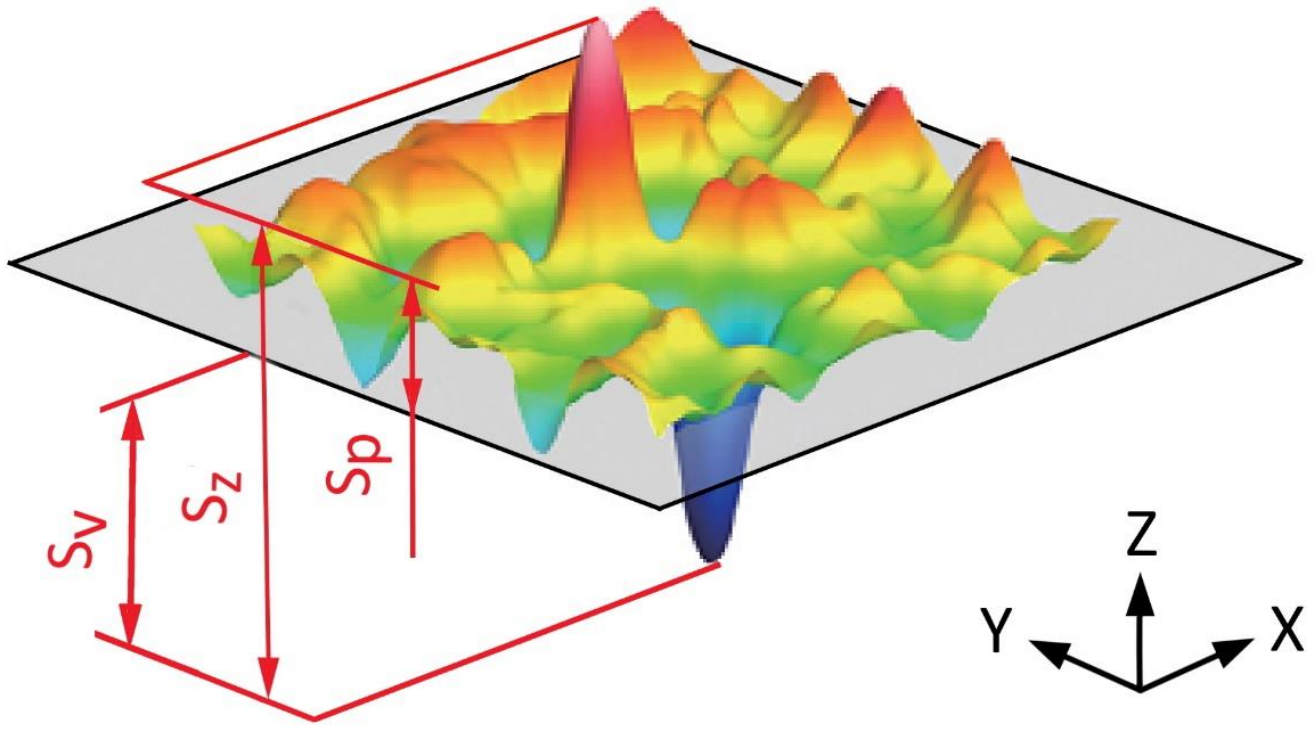

Figure 3. Detail of $S_{z}$ roughness factor 
$\mathrm{S}_{\mathrm{z}}$ may find application for sealing systems, surface cosmetic appearance and may be related to the degree of surface wetting by various fluids.

\section{Results and discussion}

The cutting samples was tested for two output parameters: cutting depth and surface roughness $S_{Z}$. The cutting depth was measured on the digital high gauge and the surface roughness with Olympus LEXT ${ }^{\mathrm{TM}}$ OLS5100 laser scanning microscope combines unique accuracy and optical implementation with smart tools. The results of the two output parameters were given in the Table 3.

Table 3. Control and output parameters

\begin{tabular}{cccccc}
\hline Test nr. & AFR & Pressure & Traverse speed & Dc & Sz \\
\hline 1 & 450 & 400 & 300 & 11.05 & 74.71 \\
2 & 450 & 375 & 200 & 13.07 & 90.10 \\
3 & 450 & 350 & 100 & 19.81 & 55.26 \\
4 & 350 & 400 & 200 & 13.75 & 62.09 \\
5 & 350 & 375 & 100 & 19.66 & 63.91 \\
6 & 350 & 350 & 300 & 8.37 & 76.18 \\
7 & 250 & 400 & 100 & 20.30 & 59.80 \\
8 & 250 & 375 & 300 & 8.04 & 61.63 \\
9 & 250 & 350 & 200 & 10.74 & 79.145 \\
\hline
\end{tabular}

For the laboratory results, the specific desirability values were obtained using equations (1) for cutting depth and (2) for surface roughness. Finally, on base the individual desirability the composite desirability $\left(d_{i}\right)$ using the equation (4) was calculated. For finding the composite desirability equal weightage is assumed i.e., 0.5 for both the output characteristics. All determined values are given also in the Table 4 .

Table 4. Individual and composite desirability values of outputs and its rank

\begin{tabular}{ccccccc}
\hline Test nr. & $\mathrm{D}_{\mathrm{c}}$ & $\mathrm{S}_{\mathrm{z}}$ & $\mathrm{d}_{\mathrm{i}(\mathrm{Dc})}$ & $\mathrm{d}_{\mathrm{i}(\mathrm{Sz})}$ & $\mathrm{d}_{\mathrm{i}}$ & Rank \\
\hline 1 & 11.05 & 74.71 & 0.48 & 0.64 & 0.55 & 5 \\
2 & 13.07 & 90.10 & 0.62 & 0.00 & 0.00 & 8 \\
$\mathbf{3}$ & $\mathbf{1 9 . 8 1}$ & 55.26 & 0.95 & 0.96 & 0.96 & 1 \\
4 & 13.75 & 62.09 & 0.66 & 0.86 & 0.76 & 4 \\
5 & 19.66 & 63.91 & 0.94 & 0.84 & 0.89 & 3 \\
6 & 8.37 & 76.18 & 0.16 & 0.61 & 0.31 & 7 \\
7 & 20.3 & 59.80 & 0.97 & 0.90 & 0.93 & 2 \\
8 & 8.04 & 61.63 & 0.00 & 0.87 & 0.00 & 8 \\
9 & 10.74 & 79.145 & 0.46 & 0.54 & 0.50 & 6 \\
\hline \multicolumn{7}{c}{ In bold is marked set of 1 rank control parameters values } \\
\hline
\end{tabular}

The mean of factor influences at each level on $\mathrm{d}_{\mathrm{i}}$ was calculated and given in Table 5 and depicted in Fig. 4. The highest mean $d_{i}$ is obtained at AFR equal $350 \mathrm{~g} / \mathrm{s}$, pressure equal $400 \mathrm{MPa}$, and traverse speed equal $100 \mathrm{~mm} / \mathrm{min}$. Hence, the optimum parameter setting for the simultaneous optimization of cutting depth and surface roughness is obtained at these values of control parameters.

The biggest influence on the on $d_{i}$ factor was observed for traverse speed is found significant followed by pressure, and AFR. Similar conclusions can be drawn from Fig. 4. 
Table 5. Response table Factors Mean composite desirability factor effect

\begin{tabular}{|c|c|c|c|c|c|}
\hline \multirow{3}{*}{ Factors } & \multicolumn{3}{|c|}{ Mean composite desirability } & \multirow{3}{*}{ Factor effects } & \multirow{3}{*}{ Rank } \\
\hline & \multicolumn{3}{|c|}{ Levels } & & \\
\hline & 1 & 2 & 3 & & \\
\hline AFR & 0.4929 & 0.6743 & 0.5212 & 0.1814 & 3 \\
\hline Pressure & 0.6083 & 0.3062 & 0.7739 & 0.4677 & 2 \\
\hline Traverse speed & 0.9581 & 0.4317 & 0.2986 & 0.6595 & 1 \\
\hline
\end{tabular}
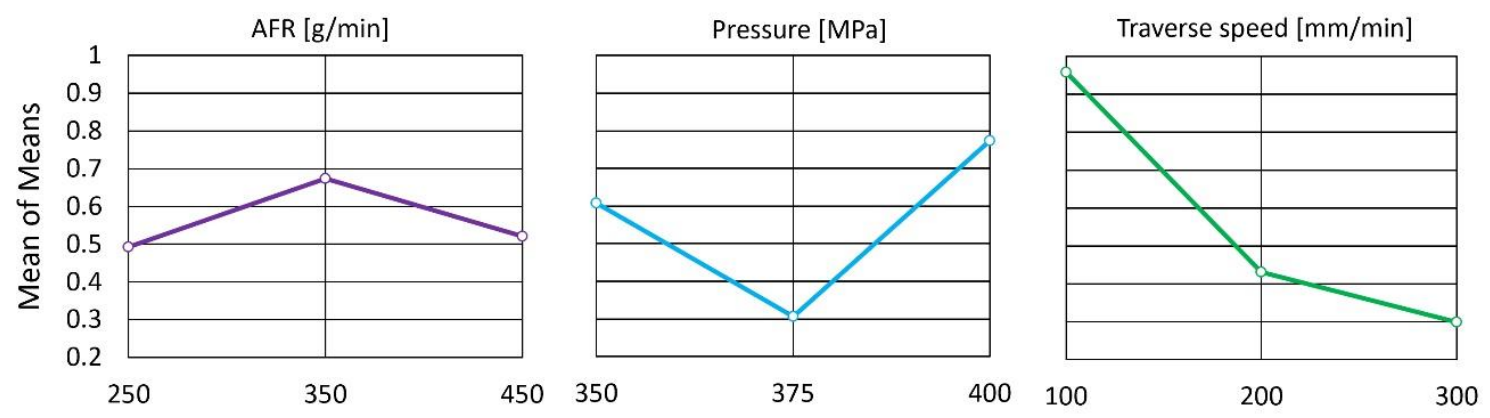

Figure 4. Main effect chart on $d_{i}$ factor

The next step to improve the effects measures was conducted the additional lab cutting test, at control parameters condition shown in Table 5 and Fig 4. The result of validation and improvement in performance measures are presented in Table 6. Improvement in relation to the initial optimal value observed in cutting depth noted as $6.31 \%$ and in surface roughness $S_{z}$ as $5.18 \mu \mathrm{m}$.

Table 6. Improvement in cutting depth and Surface roughness

\begin{tabular}{ccccccc}
\hline \multirow{2}{*}{$\begin{array}{c}\text { Test } \\
\mathrm{Nr}\end{array}$} & Description & AFR & Pressure & $\begin{array}{c}\text { Traverse } \\
\text { speed }\end{array}$ & Cutting depth $\mathrm{D}_{\mathrm{c}}$ & $\begin{array}{c}\text { Surface } \\
\text { Roughness } \mathrm{S}_{\mathrm{z}}\end{array}$ \\
\cline { 3 - 7 } & & {$[\mathrm{g} / \mathrm{min}]$} & {$[\mathrm{MPa}]$} & {$[\mathrm{mm} / \mathrm{min}]$} & {$[\mathrm{mm}]$} & {$[\mu \mathrm{m}]$} \\
\hline 2 & Initial optimum & 450 & 350 & 100 & 19.81 & 55.26 \\
10 & Improved optimum & 350 & 400 & 100 & 21.06 & 52.54 \\
\hline \multicolumn{3}{c}{ Improvement } & & $6.31 \%$ & $5.18 \%$ \\
\hline
\end{tabular}

\section{Conclusions}

Experiments was conducted as per Taguchi L9 orthogonal array with three control process variables, each at three levels. Predictive performance was validated using confirmation test. The primary aim of this research was to obtain the optimal set of control parameters that affect the cutting depth and the surface roughness in the presence of multiple responses. The conducted research confirmed the equity of applying the method in multi-criteria optimization of the Hardox steel cutting process by AWJ and confirmed improvement in performance measures.

On the basis the DFA graph concluded that the best possible combination of the process parameters to optimize the output parameters is: abrasive flow rate $=350 \mathrm{~g} / \mathrm{min}$, pressure $=400 \mathrm{MPa}$, traverse speed $=100$ $\mathrm{mm} / \mathrm{min}$.

The change in traverse speed causes the biggest changes in effects, next by the abrasive flow rate and the smallest impact was noted for the pressure output.

The proposed methodology of simultaneous optimization can be used also to optimize 4-5 responses, and robustness can be checked. DFA can be carried out with different weights assigned to responses, and results can be compared. Further, a suitable technique can be used for weight optimization. Application of other optimization techniques such as GRA and VIKOR can also be explored. 


\section{References}

Alagarsamy, S. V., Ravichandran, M., \& Saravanan, H. (2021). Development of Mathematical Model for Predicting the Electric Erosion Behavior of $\mathrm{TiO}_{2}$ Filled Al-Zn-Mg-Cu (AA7075) Alloy Composite Using RSM-DFA Method. Journal of Advanced Manufacturing Systems $20 \quad$ (01): 1-26. https://doi.org/10.1142/S0219686721500013.

Balasz, B., Szatkiewicz, T., \& Krolikowski, T. (2007). Grinding Wheel Topography Modeling with Application of an Elastic Neural Network. Edited by Huang, DS and Heutte, L and Loog, M. Advanced Intelligent Computing Theories and Applications, Proceedings: With Aspects of Artificial Intelligence. Lecture Notes in Artificial Intelligence, Berlin, Germany, Springer-Verlag 2007.

Chanakyan, C., \& Sivasankar, S. (2020). Parametric Studies in Friction Stir Welding on Al-Mg Alloy with (HCHCr) Tool by Taguchi Based Desirability Function Analysis (DFA). Journal of Ceramic Processing Research 21 (6): 647-55. https://doi.org/10.36410/JCPR.2020.21.6.647.

Derringer, G., \& Suich, R. (1980). Simultaneous Optimization of Several Response Variables. Journal of Quality Technology 12 (4): 214-19. https://doi.org/10.1080/00224065.1980.11980968.

Devarajaiah, D., \& Chandrasekaran, M. (2018). Evaluation of Power Consumption and MRR in WEDM of Ti-6Al-4V Alloy and Its Simultaneous Optimization for Sustainable Production. Journal of the Brazilian Society of Mechanical Sciences and Engineering 40 (8): 400. https://doi.org/10.1007/s40430-018-1318-y.

Dhanawade, A., \& Shailendra, K. (2019). Abrasive Water Jet Machining of Carbon Epoxy Composite: Cutting Performance, Predictive Models and Optimization. Indian Journal of Engineering and Materials Science 26 (3-4): 265-75.

Fajdek-Bieda, A. (2021). Using Entropy-VIKOR Method in Chemical Processes Optimization. Procedia Computer Science 192: 4208-17. https://doi.org/10.1016/j.procs.2021.09.197.

Gostimirovic, M., Pucovsky, V., Sekulic, M., Rodic, D., \& Pejic, V. (2019). Evolutionary Optimization of Jet Lag in the Abrasive Water Jet Machining. International Journal of Advanced Manufacturing Technology 101 (9-12): 3131-41. https://doi.org/10.1007/s00170-018-3181-5.

Harrington, J. (1965). The Desirability Function. Industrial Quality Control 21: 494-98.

“Jinhong Mining Catalog of Products.”. Lianyungang Jinhong Mining Co. Ltd. October 10, 2019. http://www.lygjhky.com/Hva_En/Catalog.pdf, (access 11.10.2021).

Krolczyk, G., Kacalak, W., \& Wieczorowski, M. (2021). 3D Parametric and Nonparametric Description of Surface Topography in Manufacturing Processes. Materials, Basel, Switzerland, MDPI. https://doi.org/10.3390/ma14081987.

Bouzid, L., Athmane, Y.M., Belhadi S., \& Haddad, A. (2020). Modelling and Optimization of Machining Parameters during Hardened Steel AISID3 Turning Using RSM, ANN and DFA Techniques: Comparative Study. Journal of Mechanical Engineering and Sciences 14 (2): 6835-47. https://doi.org/10.15282/jmes.14.2.2020.23.0535.

Panda, S.N., Bagal, D.K., Kumar, A., Patnaik, D., Barua, A., Jeet, S., Parida, B., \& Naik, B. (2020). Comparative Evaluation for Studying the Parametric Influences on Quality of Electrode Using Taguchi Method Coupled with MOORA, DFA, and TOPSIS Method for Electrochemical Machining. In Recent Advances in Mechanical Infrastructure, edited by Ajit Kumar Parwani and Pl. Ramkumar, 115-29. Lecture Notes in Intelligent Transportation and Infrastructure. Singapore: Springer Singapore. https://doi.org/10.1007/978-98132-9971-9_13.

Perec, A. (2021). Multiple Response Optimization of Abrasive Water Jet Cutting Process Using Response Surface Methodology (RSM). Procedia Computer Science 192: 931-40. https://doi.org/10.1016/ j.procs.2021.08.096.

Radomska-Zalas, A, Perec, A., \& Fajdek-Bieda, A. (2019). IT Support for Optimisation of Abrasive Water Cutting Process Using the TOPSIS Method. IOP Conference Series: Materials Science and Engineering 710 (December): 012008. https://doi.org/10.1088/1757-899X/710/1/012008. 
Radomska-Zalas, A., \& Fajdek-Bieda, A. (2021). IT Support for the Optimization of the Epoxidation of Unsaturated Compounds on the Example of the TOPSIS Method. In Intelligent Decision Technologies, edited by Ireneusz Czarnowski, Robert J. Howlett, and Lakhmi C. Jain, 238:297-307. Smart Innovation, Systems and Technologies. Singapore: Springer Singapore. https://doi.org/10.1007/978-981-16-2765-1_25.

Radomska-Zalas, A., \& Perec, A. (2019). Modeling of Abrasive Water Suspension Jet Cutting Process Using Response Surface Method. In AIP Conference Proceedings, 2078 Issue 1:0200511-18. Volume 2078. Melville: AIP Publishing. https://doi.org/10.1063/1.5092054

SSAB Homepage. Accessed October 10, 2021. https:/www.ssab.com/products/brands/hardox/products/ hardox-500, (access 11.10.2021). 